Statement by the Managing Director on the Independent Evaluation Office Report on Growth and Adjustment in IMF-Supported Programs 


\section{Statement by the Managing Director on the Independent Evaluation Office Report on Growth and Adjustment in IMF-Supported Programs Executive Board Meeting August 30, 2021}

I welcome the report of the Independent Evaluation Office (IEO) on Growth and Adjustment in IMF-Supported Programs, including the background papers and country case studies. The report offers valuable analysis and recommendations and comes at a very opportune time, as Fund lending is at an all-time high. I agree with the overall assessment, which is broadly consistent with staff's 2018 Review of Program Design and Conditionality (ROC). I also broadly agree with the recommendations, which will be an important input into the ongoing review of the operational guidance note on conditionality, expected to be finalized in 2022.

I am pleased with the IEO conclusion that there is no evidence of a consistent bias towards excessive austerity in IMF-supported programs during the evaluation period. I also agree with the finding that Fund-supported programs have yielded growth benefits relative to a counterfactual of no Fund engagement and that stabilization and reforms implemented in the program context boosted post-program growth performance. I welcome the IEO's finding that fiscal multiplier assumptions were broadly in line with the guidance given to staff and the empirical literature. I should add in this respect that, as seen in some programs, macro-financial considerations may affect growth outcomes directly or condition the size of fiscal multipliers, and the composition of an adjustment path can affect growth outcomes. Thus, staff should continue striking a balance between the general guidance and consideration of country-specific policy circumstances.

I acknowledge the IEO's assessment that the limited use of exchange rate adjustment as a tool in a program context may suggest that there could be greater scope to use exchange rate policy as a means to facilitate adjustment while supporting growth and resilience to adverse shocks. I would like to emphasize nevertheless that there is no one-size-fits all approach, with the need for a case-by-case assessment of individual country circumstances. In some cases, the use of the exchange rate is not possible due to regional currency arrangements, large negative spillover 
risks, and ultimately national decisions on the exchange rate regime, which the IEO also acknowledges.

I also take note of the IEO's finding that successful debt operations can contribute to progress in lowering debt trajectory and restoring growth. While I agree in general with the need to avoid "too little and too late" debt restructurings, I would also like to emphasize that the Fund has a duty of neutrality, as also mentioned by the IEO, and has a limited role in debt restructuring operations. I am pleased to say that the impact and consequence of debt operations on growth and market access is already captured as one of the relevant economic risks in recent IMF/ World Bank work, while the new MAC DSA guidance note would cover macro projections and realism issues.

\section{RESPONSE TO IEO RECOMMENDATIONS}

\section{Recommendation 1. Attention to growth implications of IMF-supported programs should become more thorough, systematic, realistic, and sensitive to social and distributional consequences.}

\section{I support this recommendation, with some qualifications.}

I broadly concur with this recommendation. In particular, I agree with the need for more thorough discussion on growth issues in IMF-supported programs (both GRA and PRGT), and I would highlight that staff reports for program requests and reviews should — and many already do-discuss the growth strategy on a case-by-case basis, if critical to the program success.

In this context, I would echo the IEO's message that the ongoing revisions to the operational guidance note on conditionality will provide an opportunity to update guidance on program design and conditionality, based on the findings of the 2018 ROC regarding over-optimistic growth assumptions and of this IEO evaluation.

At the same time, while it is important to support economic adjustment and reforms for sustained growth over the medium term (e.g., fiscal balance targets or debt sustainability), growth cannot be placed above or on par with the core objective of Fund lending of helping members resolve their balance of payments problems, according to our Articles of Agreement. The focus needs to be on how we can provide further guidance on the role of Fund-supported programs in fostering sustainable growth, taking into account the quality of growth. 
While I support the sub-recommendation to discuss fiscal multiplier assumptions, I would stress the need for a flexible application of tools, as fiscal multipliers are often difficult to assess ex ante, and even harder during crises.

I also concur with the sub-recommendation to pay more consistent attention to contingencies for growth shortfalls. In this regard, I would like to emphasize the importance of a case-by-case approach to developing contingency plans, depending on country circumstances. Importantly, program reviews already discuss key program risks, including growth shocks, and allow for program modifications in response to unforeseen shocks. Finally, in some cases, contingency discussions with the authorities need to be confidential to avoid adverse market reactions.

Finally, I agree with strengthening the monitoring of key social and distributional metrics where feasible. I would, however, also note that limited data availability - particularly in countries with a large informal sector and weak household-level data - and possible budgetary implications for the Fund may limit a broader application to all programs. While some country teams already examine distributional consequences of adjustment and reform policies, a more systematic incorporation of such assessments in program design would require specialized staffing.

\section{Recommendation 2. IMF-supported programs should pay greater attention to supporting deep, more growth-oriented structural reforms with more effective capacity development support and more effective collaboration with partners in areas outside the Fund's core mandate and expertise.}

\section{I support this recommendation.}

I agree with focusing more on growth-oriented structural reforms, effective capacity development (CD) and collaborating with partners such as the World Bank. I concur with a more effective collaboration with partners in areas outside the Fund's core mandate and expertise, including the World Bank. I would emphasize that staff — in program cases in particulartypically collaborate closely with World Bank counterparts on a range of topics, including structural fiscal issues and social support to financial development. I am pleased to state that avenues for further cooperation are being pursued in the context of the ongoing MIP for IMF Collaboration with the World Bank on Macro-Structural Issues. As the IEO correctly implies, expanding SC beyond the Fund's core expertise should recognize the need for Fund conditionality to be independently verifiable and monitorable by Fund staff, which also requires 
inhouse expertise, while cross-conditionality (linking the use of Fund resources to the rules and decisions of other organizations) is disallowed.

I would also note that the Board-endorsed recommendations of the $2018 \mathrm{ROC}$ called for SC to be parsimonious, also reiterated by the IEO, and better prioritized in line with program objectives. The 2018 IEO evaluation update of SC in IMF-supported programs also found the SC in core Fund expertise to be associated with better implementation. I would thus caution against veering too far out of areas of the Fund's core mandate and expertise.

I agree that the Fund could revisit how CD support is integrated with program design and implementation, with the aim to promote deeper and more successful reform efforts in a program context. I look forward to the ongoing IEO evaluation of IMF CD, including how the coordination of Fund-supported programs and CD activities could be improved further, as well as the next strategic review of IMF CD work in 2023. I would note that the benefits of more effective CD in Fund-supported programs also depend on the country's implementation capacity. For a fuller picture, the costs associated with CD activities would also need to be fully reflected in the IEO report.

\section{Recommendation 3-The Fund should continue to invest in building a toolkit of models and monitors that can be applied as a basis for analysis of the adjustment-growth relationship and assessing growth-related developments in the program context.}

\section{I support this recommendation.}

I support further developing and refining our toolkit of models. A number of such models (DIG, DIGNAR, new RES model, and FAD's SDG financing model that “endogenizes” growth) are already available for both program and surveillance purposes. Moreover, an ongoing ICD initiative on Modernizing Financial Programming Toolkit ("FP 2.0") aims to build a tractable modeling toolkit and to design user-friendly ways to apply the modeling tools, calibrate baseline projections, reflect expected growth impacts of policy measures, and build risk scenarios.

I agree that teams should be encouraged to make use of the available modeling resources and the new models on a case-by-case basis; further investment in the RES structural reform database could be indeed helpful. 
Table 1. The Managing Director's Position on IEO Recommendations

\begin{tabular}{|l|l|}
\hline Recommendation & Position \\
\hline $\begin{array}{l}\text { 1. Attention to growth implications of IMF-supported programs } \\
\text { should become more thorough, systematic, realistic and } \\
\text { sensitive to social and distributional consequences. }\end{array}$ & Qualified Support \\
\hline $\begin{array}{l}\text { 2. IMF-supported programs should pay greater attention to } \\
\text { supporting deep, more growth-oriented structural reforms with } \\
\text { more effective capacity development support and more } \\
\text { effective collaboration with partners in areas outside the Fund's } \\
\text { core mandate and expertise. }\end{array}$ & Support \\
\hline $\begin{array}{l}\text { 3. The Fund should continue to invest in building a toolkit of } \\
\text { models and monitors that can be applied as a basis for analysis } \\
\text { of the adjustment-growth relationship and assessing growth- } \\
\text { related developments in the program context. }\end{array}$ & Support \\
\hline
\end{tabular}

